\title{
Molecular cloning and functional analysis of a necrosis and ethylene inducing protein (NEP) from Ganoderma boninense
}

\begin{abstract}
Fungal necrosis and ethylene inducing proteins (NEPs) induce cell death and elicit strong immune responses in many crops. In this study, we report the cloning and characterization of a transcript encoding NEP from Ganoderma boninense which belongs to a family of fungi in Ganodermataceae that cause serious infections of cacao, rubber, tea, coffee and palms. The open reading frame (ORF) encoding NEP inG. boninense(GbNEP) was cloned by 5'and 3 'rapid amplification of cDNA ends (RACE) PCR. The transcript abundance of GbNEP increased in fungal culture treated with salicylic acid and jasmonic acid, respectively. The soluble recombinant Gb EP expressed in Escherichia coli BL21(DE3) pLysS was able to induce necrosis in tobacco and tomato but ineffective when applied to oil palm leaves and root tissues. The recombinant GbNEP could induce localized cell death, and production of hydrogen peroxide and superoxide in tobacco leaves. The addition of $\mathrm{LaCl} 3$ (a calcium channel inhibitor) and EGTA (a Ca2+chelator) to tobacco leaves prior to the challenge with GbNEP significantly reduced the necrosis symptoms indicating that $\mathrm{Ca} 2+$ is required for the action of GbNEP. In summary, this is the first report of NEP from Ganoderma species which may contribute to further research on the role of GbNEP during disease development.
\end{abstract}

Keyword: Ganoderma; Necrosis and ethylene inducing protein; Recombinant protein; Dicots; Monocots 